\title{
Persian Gardens: Meanings, Symbolism, and Design
}

\author{
Leila Mahmoudi Farahani*, Bahareh Motamed, Elmira Jamei \\ Deakin University, School of Architecture and Built Environment, 1 Gheringhap St, Geelong; 3220, Australia
}

\begin{abstract}
Culture and identity in a society can be represented in the architecture and the meanings intertwined with it. In this sense, the architecture and design are the interface for transferring meaning and identity to the nation and future generations. Persian gardens have been evolved through the history of Persian Empire in regard to the culture and beliefs of the society. This paper aims to investigate the patterns of design and architecture in Persian gardens and the meanings intertwined with their patterns and significant elements such as water and trees. Persian gardens are not only about geometries and shapes; but also manifest different design elements, each representing a specific symbol and its significance among the society. This paper seeks to explore Persian gardens in terms of their geometric structure, irrigation system, network construction and pavilions alongside design qualities such as hierarchy, symmetry, centrality, rhythm and harmony. In the second stage, the paper investigates the fundamental symbols and their philosophy in the creation of Persian gardens and in relation to the architecture and design.
\end{abstract}

\section{Keywords:}

Persian gardens, symbolism, meaning, culture, chahar-bagh

\footnotetext{
*Corresponding author. Email: Imahmoud@deakin.edu.au
}

(C) The Authors. 2016. Landscape Online. This is an Open Access article distributed under the terms of the Creative Commons Attribution License (http://creativecommons.org/licenses/by/4.0), which permits unrestricted use, distribution, and reproduction in any medium, provided the original work is properly cited. 


\section{Introduction}

G arden has been defined as 'the purest of human pleasures and the greatest refreshment to the spirits of man' (Bacon 1883). According to Hunt, gardens are "concentrated or perfected forms of place-making' (Hunt 2000). Garden is also perceived as a symbolic site, resulting from the human's attempts to materialize Eden on the earth (AlonMozes 2004). In the Greek text of the Bible, a garden has been expressed as a "paradise". In Hebrew "Eden" is translated to an unidentified region or country. In Persian literature, the word garden "pardis" derives from the word "paridaiza" which literally means "walled garden" and it has been summed up as a luminous and perfumed place, populated by a number of angelical and beautiful creatures (Babaie 1997).

The earliest evidence of Persian gardens was recorded in 600 B.C. at the Palace area in Pasargadae and dates back to the final years of the reign of Cyrus the Great (559-30 B.C.). The garden was based on the Zoroastrian division of the universe into four parts, four seasons or the four elements; water, wind, soil and fire (Karimi-Hakkak 1998). A mystical feeling for flowers and a love of gardens are integral parts of ancient Persian gardens. The Persian garden is a manifestation of supreme values and concepts and is well-known as a bridge connecting the two worlds of matter and meaning.

The philosophical design concept of Persian gardens is believed to be rooted in the four sacred elements of water, wind, fire and soil. The geometrical design of Persian gardens has been reflected in Persian carpets, potteries and visualarts. The other distinctive feature of Persian gardens, which contributes to the introspective characteristics of ancient Persian people, is the wide application of thick brick walls, which surround the entire rectangular plan of the garden. Other traits of Persian gardens include: the application of perpendicular angles and straight lines, ponds and pools to supply the water and highlight the scenic landscape view, simultaneous use of evergreen and deciduous trees, planting of various types of plants and consideration of focal a pavilion known as Kooshk.
The purpose of designing gardens in Persia, was not only limited to providing green spaces for the inhabitants, but also creating the opportunity for further interaction between the human and nature as well as creating various ranges of functions (Gharipour 2011) and promoting Persian culture via various design elements (Müller-Wille 2001). In fact, Persian gardens are not only about beautiful geometries and shapes; but they manifest different design elements, each representing a specific symbol. This paper aims to review three selected Persian gardens from the central district of Iran in terms of their design, geometry and typology which has been usually derived from their function and geographic location. It also explores the fundamental symbols and their philosophy used in the creation of Persian gardens and in relation to their architecture and design.

A considerable amount of literature has been published on the meaning and symbolism of Asian and Persian gardens (Alemi 1390; Ansari et al. 2008; Borazjani \& Javadi 2004; Shahidi et al. 2010). There is also some research on the occurrence of gardens within Persian literature, carpets, miniature and other sorts of art. However, there has been relatively little published on the application of meanings and symbolism in the design and architectural discourse of the garden. Therefore, this paper seeks to investigate how the layers of meaning in Persian gardens have penetrated to different elements and aspects of garden design. In this regard, three wellknown gardens have been selected amongst Persian gardens around the country: (1) Shahzadeh-Mahan Garden, (2) Fin Garden, and (3) Chehel Sotun Garden. All of these gardens are located in semi-desert and desert lowland zones near to the vast deserts of Iran: Dasht-e Kavir and Dasht-e Lut (Fig. 1).

In the first instance, through the investigation of the literature and analysis of selected famed gardens located in the central hot and dry district of Iran, the paper carefully investigates the patterns of design and physical qualities common in Persian gardens. Afterwards, the paper reviews the literature of Persian gardens to seek the meanings and symbolism behind the design and different elements. Lastly, the reasons behind formation of the gardens in regard to the semantic value have been discussed. 


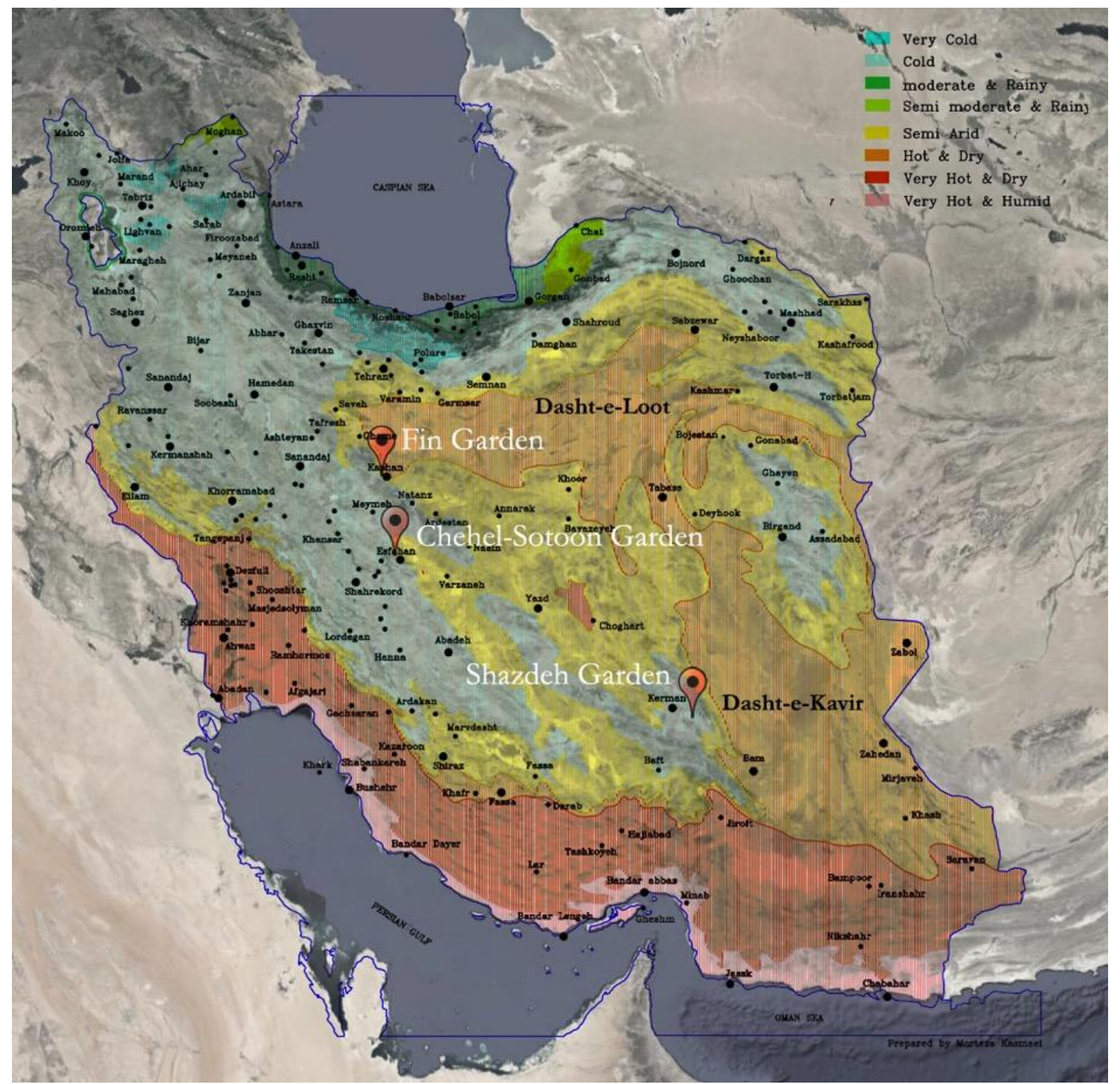

Figure 1. Placement of the three selected gardens in Iran, close to the central deserts. (Source: own work)

\section{Persian Gardens}

$\mathrm{P}$ ersian gardens were designed with a sacred geometry representing and illustrating a union of mortal/material world and the eternal universe (Khansari et al. 1998). Therefore, the geometric structure can be considered as one of the most prominent features of Persian gardens. The initial structure of Persian gardens was based on a geometrical quadripartite division with a pavilion in its intersection. The general idea of this formation was based on the pre-Islamic Iranian division of the earth into four quarters, which may have been inspired by the geometrical motifs of Mesopotamia and Sindh Valley civilizations (Massoudi 2009).

During the Islamic period, the geometric quartered pattern of Persian gardens became more reinforced by the belief of four heavenly streams; as it was similar to the image of the heaven in the Quran (Mansouri 2011). Therefore, the general pattern of most Persian gardens consisted of a rectangular space which is quartered by intersecting streams and pathways. The common irrigation system of the time has been known as another effective factor in the formation of geometric garden structure besides the impact of Persian beliefs and morals (Naghizadeh 2013). 
In this paper, the structure and spirit of Persian gardens will be investigated in three selected fame Persian gardens, which have been registered in the UNESCO's World Heritage List. These gardens have been selected based on their location and their period of constructions. They are all located in the hot and dry climate of central district of Iran and have been built between Safavid dynasty (15011736) and Qajar dynasty (1785 to 1925). Fin and Chehel-Sotun gardens are two of the oldest standing gardens in Iran, which have been built in the Safavid Dynasty.

Fin is a historic garden and palace located a few kilometres outside of Kashan just by the outskirt of Silak hills in the desert. The garden which has been positioned in a desert has been there since the ancient time. Even middle ages travellers have referred to this garden as a green and cool climate stop (Faghigh et al). The existing garden has been built by the famous Safavid Kin, Shah Abbas in the 17 th century to honour Shah Ismail, who was the first Safavid ruler. However, some parts of the structure were restored or added to the garden during Qajar dynasty. Other than hosting royal ceremonies in both Safavid and Qajar dynasty, Fin is a historical site as the most famous prime minister of Qajar, Amir Kabir, was murdered in the garden's bath house. Transforming the garden to a national monument increased people attention to this garden.

Chehel Sotun garden was built in the 1640 s by Safavid King, Shah Abbas II, in a 15-acre site in the heart of Isfahan plain, situated at the centre of the Iranian plateau. At the time, Isfahan was the capital of the Safavid Empire. The garden is located close to the most important square of the city, Naghsh-e Jahan Square, and was used for royal ceremonies and official receptions.

The last garden is the desert isolated garden of Shahzadeh (Prince) Mahan, which is located at a point $35 \mathrm{~km}$ from south-eastern Kerman near a village called Mahan. The garden was built in Qajar dynasty (1850-70) in a strategic fertile land in the middle of arid and barren lands, which has turned it to one of the famous gardens of Iran. Moreover, locating near the tomb of Shah Nematollah Vali, a famous Persian poet, has increased the visitor's attraction to this garden.

\subsection{Persian gardens architecture and components}

Through a superficial view, the structure of Persian gardens seems to be unsophisticated; however excavating the layers of meaning concealed behind this simplicity, demonstrates a careful representation of meanings, culture and identity. The following sections will address the common components and design elements/strategies that have been utilized in Persian gardens.

\subsubsection{Geometric structure}

A careful review of Persian gardens reveals that despite the small differences, gardens mostly follow the same structure in their location of components. Most gardens have rectangular plans and have been divided into square or pseudo-square shapes, possibly, for the ease of determining the distance between garden components and the exact placement of greeneries. Unlike western gardens, the geometric structure of Persian gardens does not follow the perspective principles rather were mostly based on creating unity and integrity (ICHHTO (The Office of Cultural Heritage of Iranian Cultural Heritage 2010). The rectangular shape might slightly change in response to different climatic situations and in regard to the sites' opportunities and limitations. The plan of Shahzadeh-Mahan Garden (in Kerman) is an extended example of chahar-bagh pattern in the shape of an elongated enclosed rectangle in which the pavilion is located in the center of the main water channels defining the north-south axis (Fig.2.a). The structure of Fin Garden (in Kashan) is also an extended form of chahar-bagh in a series of squares and rectangles with a pavilion and square basin in the center (Hobhouse 2003). The water axes defining the chahar-bagh include a main one which leads the user from the entrance gateway to the central pavilion and a secondary one with a turquoise-tiled water channel (Fig.2.b). The Chehelsotun Garden design also stretches to a square shape with a pavilion located at the intersection of the primary axis defined by two large pools and a secondary asymmetric axis with a smaller pool on the western side (Fig.2.c). 


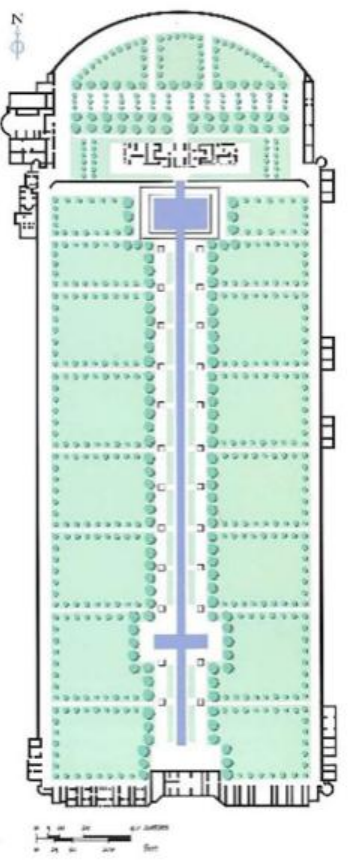

(a)

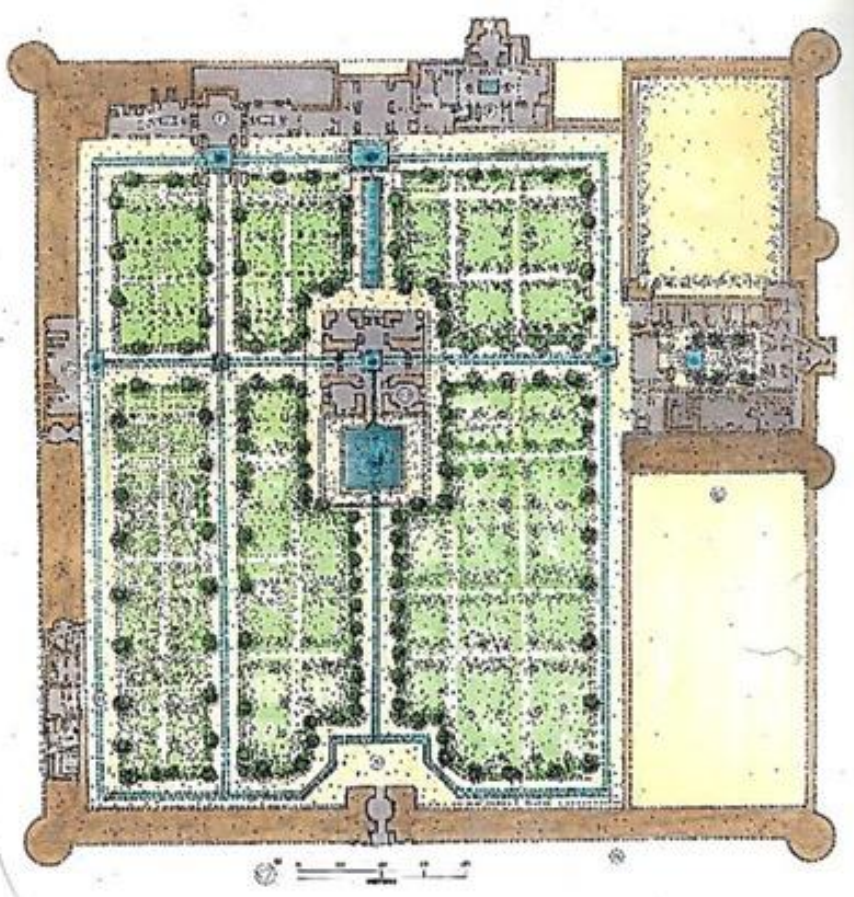

(b)

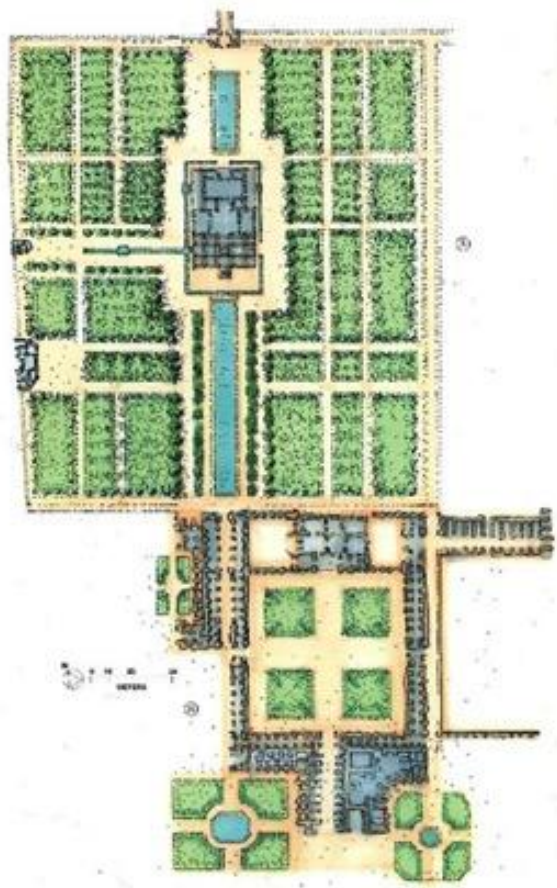

(c)

Figure 2. The geometrical structure of Persian garden Plan. (a) Shahzadeh-Mahan Garden. Kerman (Hobhouse 2003); (b) the Plan of Fin Garden, Kashan (Khansari et al. 1998); (c) the Plan of Chehel Sotun Garden, Esfahan (Khansari et al. 1998)

\subsubsection{Irrigation and fountains network}

Considering the Persian garden as an image of the paradise on earth, the water with its scarcity and limitation have been a sacred and precious element in the ancient Persia. The presence of water in Persian gardens has a dual application; a functional application of irrigation besides an ornamental and aesthetic purpose (ICHHTO (The Office of Cultural Heritage of Iranian Cultural Heritage 2010). Therefore, the pattern of chahar-bagh is usually defined with the intersected water channels or streams. The streams usually had a sufficient slope to enable the irrigation system required for the garden (Khansari et al. 1998; Pirnia 1994). The water coming from far distances into the water channels had a significant impact on the design of gardens; to the extent of the claim that the structure of gardens has been shaped according to the irrigation system (Fig. 3). Other than water channels, the front space of the pavilion was usually dedicated to a pond or large pool to reflect the image of the building and sky connecting the realm of the earthly to the heavenly.
The required water for the Fin garden has been provided by an old Sulaimaniyah Spring. The main branch furcates into the pools and water channels

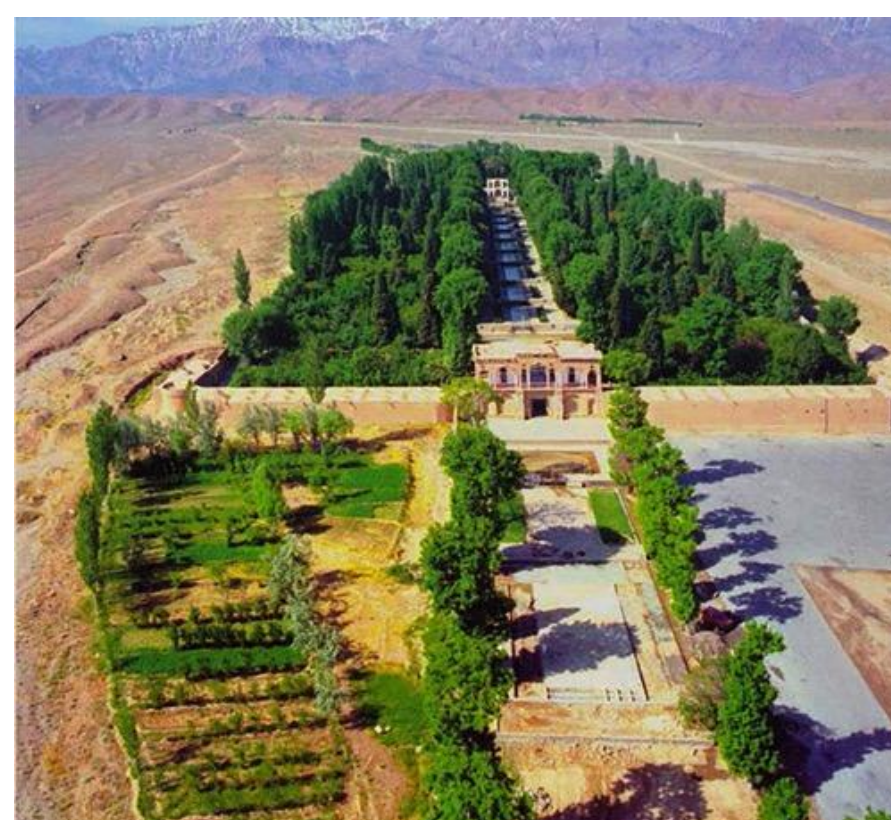

Figure 3. Aerial view of Shahzadeh-Mahan Garden in the middle of desert, Kerman, (ICHHTO The Office of Cultural Heritage of Iranian Cultural Heritage 2010) 
with several fountains (Pirnia 1994). The garden contains several streams, basins and pools which are located on the axes to circulate water around the garden (Fig. 4). The main pool of the garden is located in the central main square in front of the pavilion and there are four other pools covered by cupolas within the pavilion not only to be protected from the sun, but also intensifying the value of the water (Khansari et al. 1998).

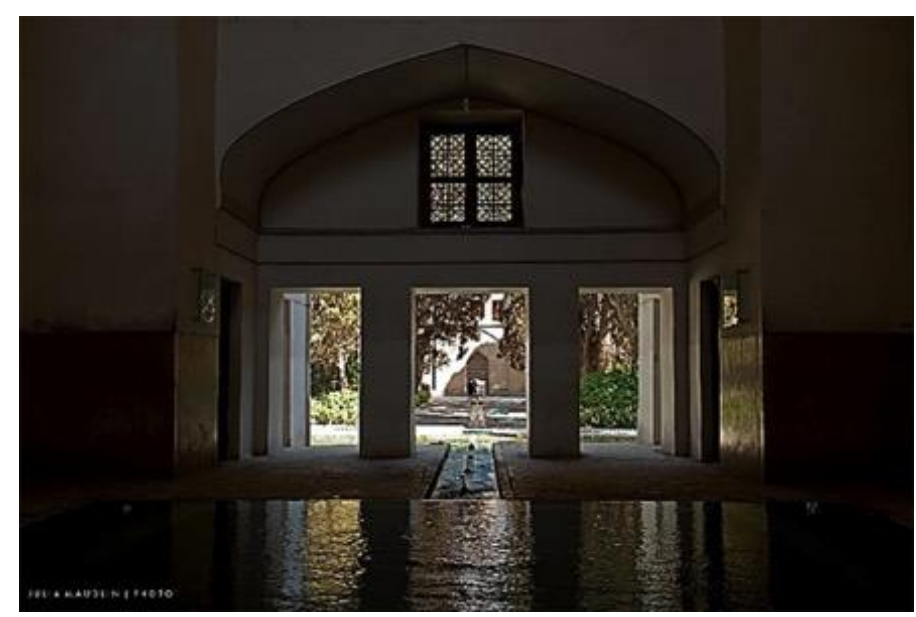

(a)

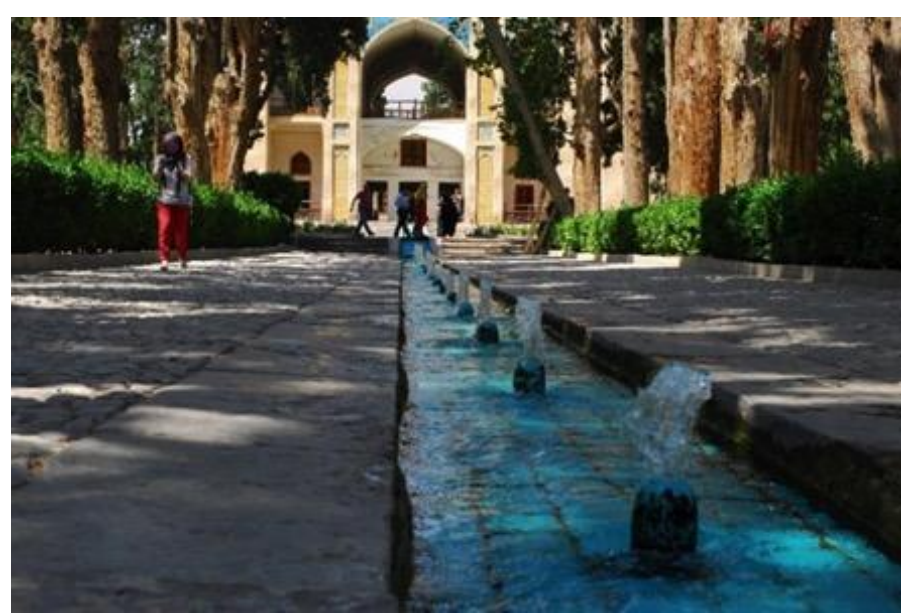

(b)

Figure 4. (a) Water way Circulation, fountains and basins in Fin Garden, Kashan. Photo by: Julia Maudlin from Flickr; (b) Water way Circulation, fountains and basins in Fin Garden, Kashan. Photo by: Shudderbug from Flickr

Garden builders utilized the slope of the land for running the water within channels, sometimes in the form of small waterfalls which not only could perform aesthetically, but also were able to act as an acoustic element throughout the garden. Shahzadeh Garden with a slope of $6.4 \%$ through the length is one of these gardens which has been designed in a stepped way to harness the slope for planting (Tajaddini 2011), with the water flowing on the steps and small fountains in the middle of the basins. The entrance is located at the lowest level of the garden and the visitor walks besides the main stream, and climbs the stairs to reach the edifice at the highest level. In some gardens such as Chehel-Sotun the small basins and fountains have been replaced by a large pool located on the main longitudinal axis of the garden (Fig. 5). In addition, the garden pavilion is surrounded by narrow streams, which are connected to the basin of the secondary axis of the garden (Khansari et al. 1998).

(a)
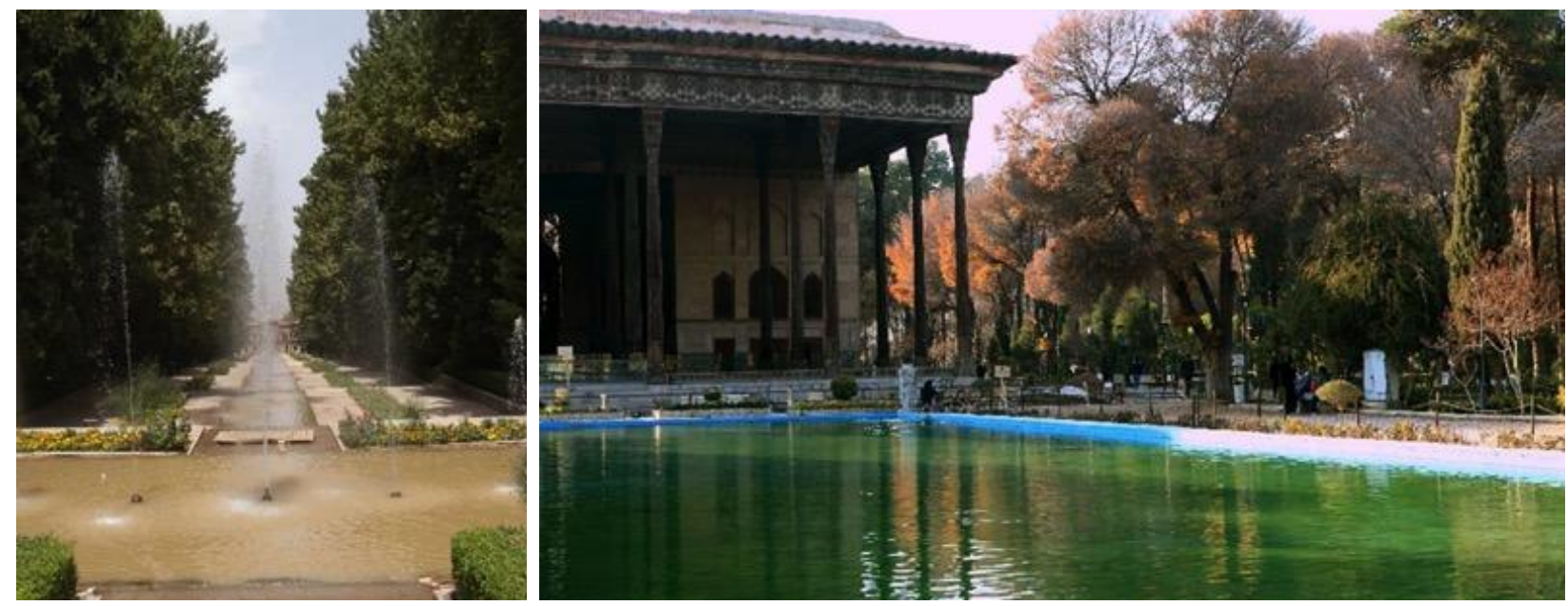

(b)

Figure 5. The system of Irrigation and water circulation in Persian gardens. (a) the view of terraced pools and streams of Shahzadeh-Mahan Garden. Photo by: Maite Elorza from Flickr; (b) The view of Central main pool of Chehelsotun garden. Photo by: Ninara from Flickr 


\subsubsection{The Entrance}

In line with the concept of introversion as an Iranian/ Islamic approach to design, gardens were surrounded by non-transparent walls. Through this inaccessible surface or boundary, defining the point of entrance becomes important. Usually the entrance has a lintel, sometimes in the form of a building or viewpoint. The entrance is usually located close to one of the axes which connects the entrance to the edifice. In the Shahzadeh Garden, the entrance has beautifully framed the pavilion and the main water channel in the center of the garden; guiding the user from the entrance to the pavilion (Fig. 6). The lintel buildings could also be used as a reception space for guests alongside defining the entrance. In some gardens such as Fin, the entrance building had a latticed wall, which would not let the outsider have a glimpse of inside and the entrance was located on the minor axis (Borazjani \& Javadi 2004).

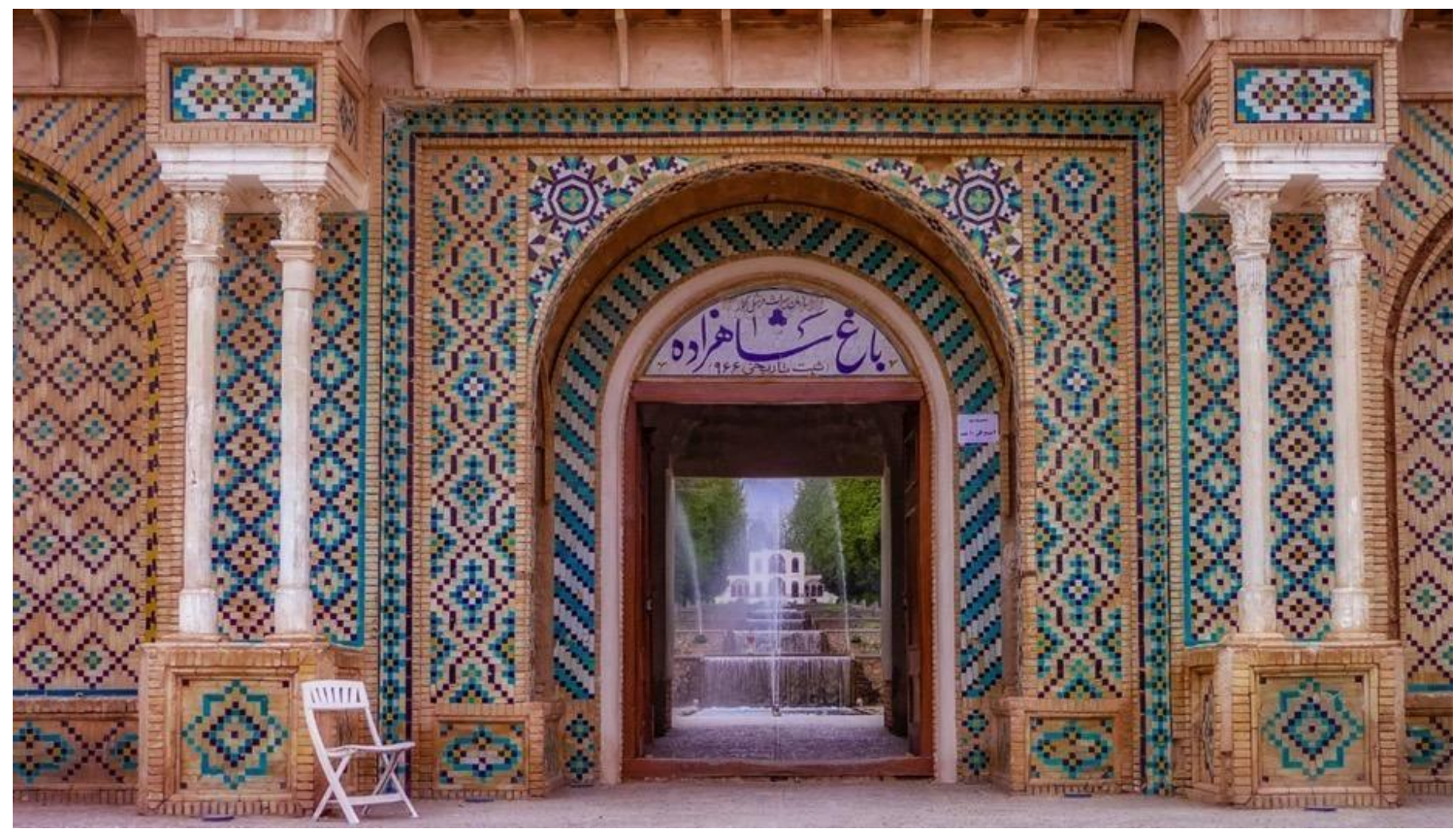

Figure 6. Lintel entrance of Shahzadeh-Mahan Garden. Source: Flicker user 'my Life, the Universe and Everything'

\subsubsection{Straight network}

The streets or footpath networks of Persian gardens were always perpendicular straight lines and coincident with the garden axes. The intersection of these main footpaths usually defines the placement of the pavilion and pool, which were located on the main longitudinal axis of the garden. These straight networks surrounded by tall trees were able to provide a desirable perspective, defining the path from the entrance to the pavilion. These networks also facilitated the access to the plots of vegetation.

\subsubsection{Pavilion}

Pavilions in Persian gardens are extroverted structures usually located at the intersection of axes with several viewpoints to the garden. Pavilions are the edifices where the residents or visitors live in and enjoy the garden. There is usually a pathway guiding the user from the entrance to the pavilion (Fig. 7). The location of the pavilion could split the garden into two to four directions. The location of pavilions could vary in different gardens. It could be located in the center of the garden or mostly it appeared 
in one third of the longitudinal axis, but it was always located at the intersection of the axes (Fig. 8). A careful analysis Persian gardens such as Fin, Shahzadeh and Chehel-Sotun reveals that the pavilions were usually located on the one third of the longitudinal axis. However, Chehel-Sotun as a governmental-ceremonial garden has had a greater palace in comparison to the other two gardens.

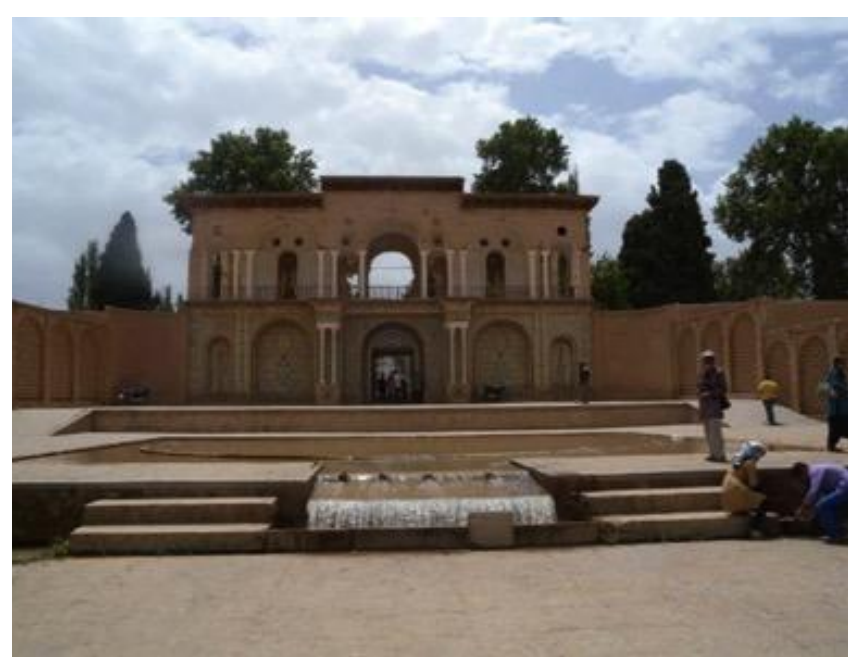

(a)

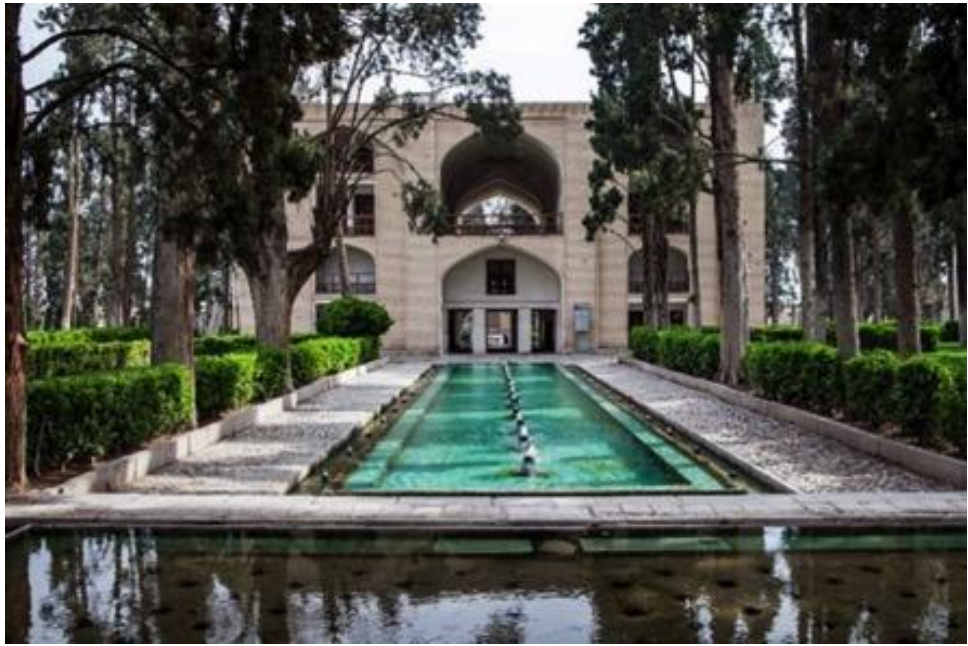

(b)

Figure 7. (a): A view of Shahzade-Mahan pavilion, Kerman. Photo by: Maite Elorza from Flickr; (b) A view of Fin garden central Pavilion, Kashan. Photo by: Ninara from Flickr

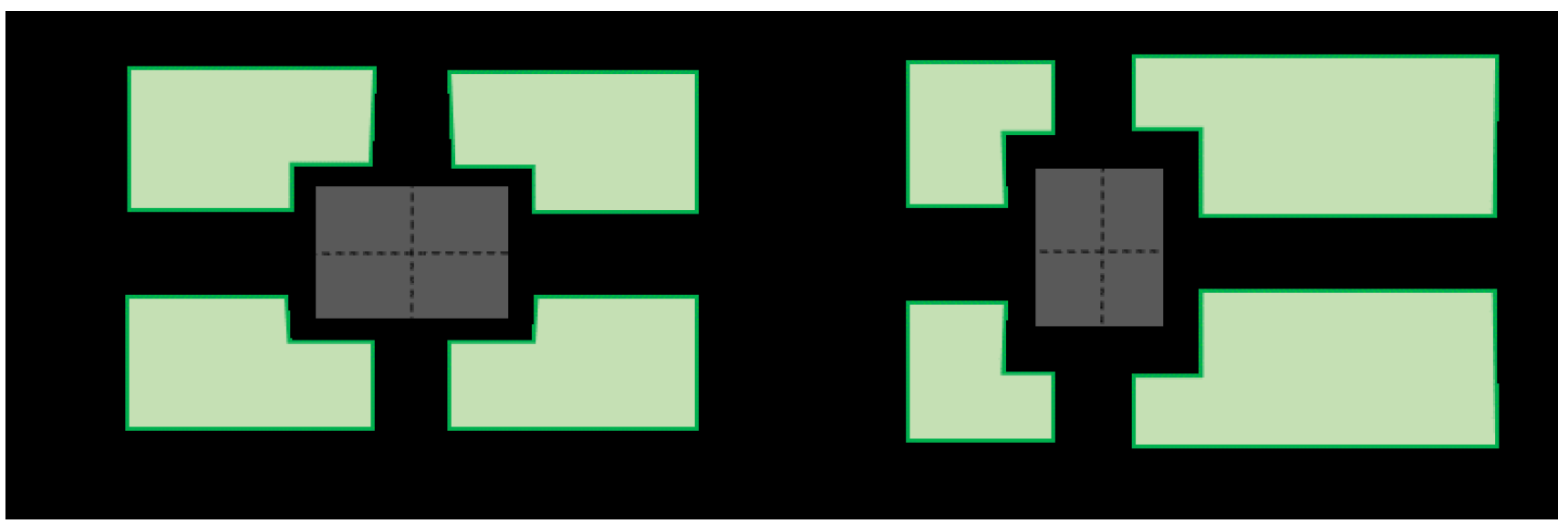

Figure 8. Schematic patterns of belvederes location in Persian gardens. (Source: author)

\subsection{Persian garden features}

A careful review of Persian gardens and the literature published on the characteristics of them reveals that these gardens usually have a similar dialogue in their conceptual attributes. This part of the paper will investigate these attributes in order to lay the groundwork for the semantic analysis.

\subsubsection{Being enclosed}

One of the unique features of Persian gardens is being fenced or walled around its perimeter.
Introversion has been rooted in Persian beliefs and culture and it is evident in almost every feature of Iranian architecture. In this sense, the whole plan and structure of Persian gardens had been enclosed within walls to provide the image of an internal paradise in the heart of deserts guarded against the eyes of strangers (Fig. 9). The function of these walls was not only to create a boundary, but also to act as an interface between the dry hot outer area and the green, shady and semi-paradise inner area (Massoudi 2009). 


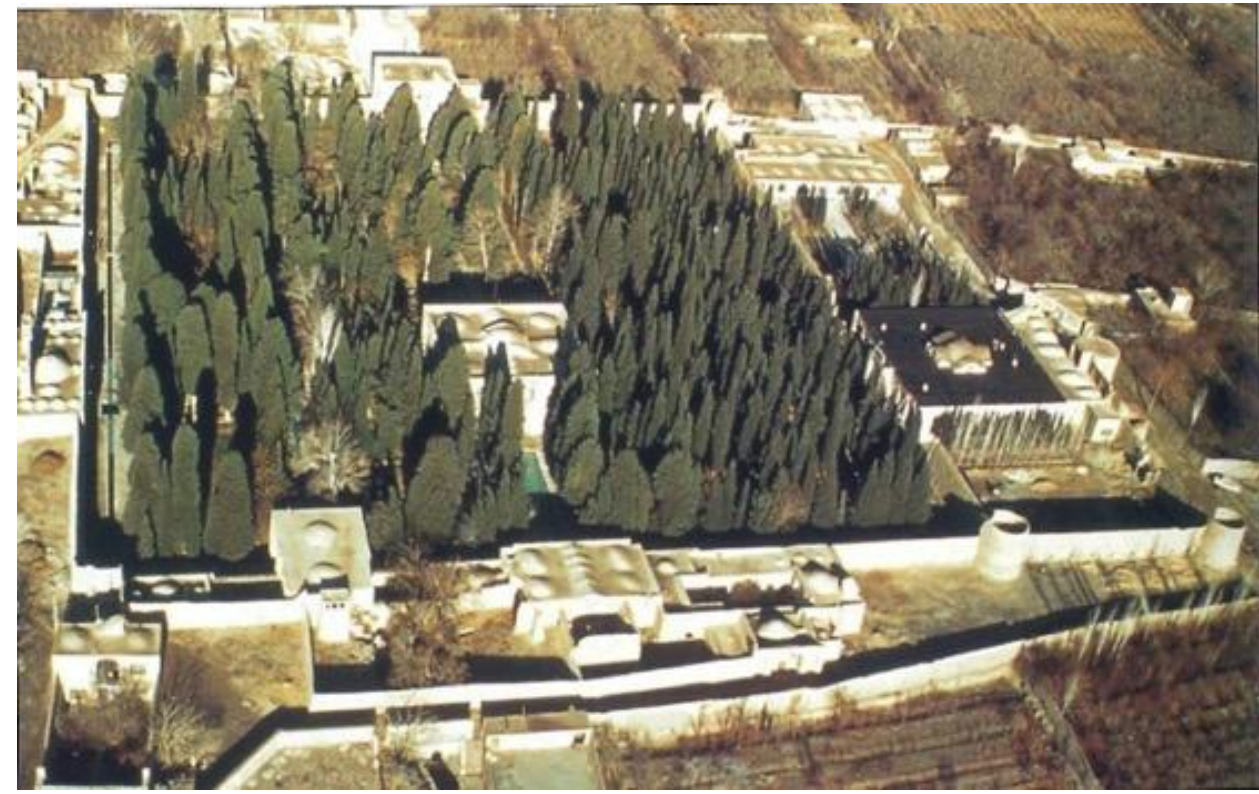

(a)

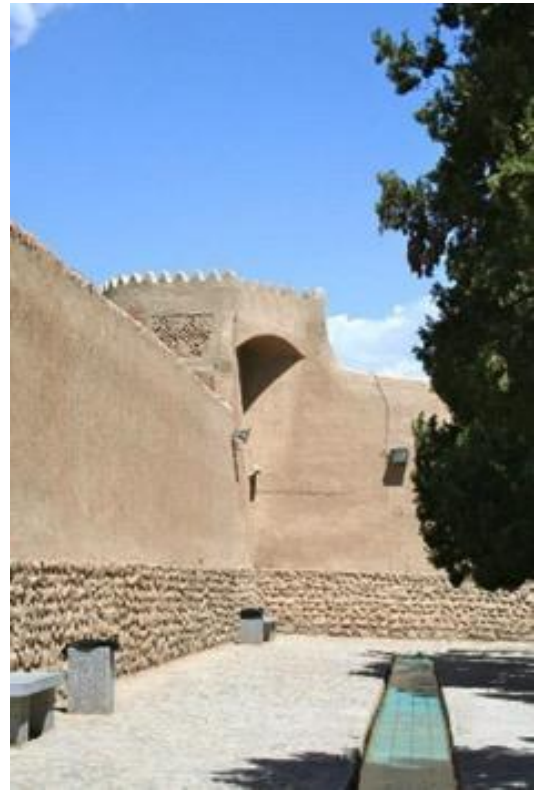

(b)

Figure 9. (a) Arial picture of Fin garden enclosed between walls (Khansari et al. 1998); (b)The Fin Garden surrounded by high walls with four towers at the corners and a monumental two level entrance in its south façade. Photo by: Azadeh Bitaraf from Flickr

\subsubsection{Hierarchy}

In order to protect the garden from outside and in line with the principle of introversion in Islamic architecture, entering the garden and the pathway to the pavilion has been designed with an accurate hierarchy. Similar to traditional houses, mosques and schools, the entrance to the garden occurs from a completely public area to a semi-public one and then to the private. Therefore, for entering the garden, you need to pass a hierarchy of spaces from the lintel into an octagonal space called "Hashti"1, and then you can see the main axis and the pavilion (Fig. 10).

Right: A plan of the Bagh-e Fin.

$A$ - Entrance building

$B$-Garden wall with the four towers at its corners

$C$ - Family quarters (Andarun)

$D$ - Pavilion built during the Qajar period, on the foundations of a pavilion from the Safavid period

E - Khalvat-e Karim Khan (now a museum)

$F$ - Bubbling basin (Howz Jushan) that receives the first water from the sping of Fin

$G$ - Pavilion (Talar)

$H$ - Batbhouse (Hammam)

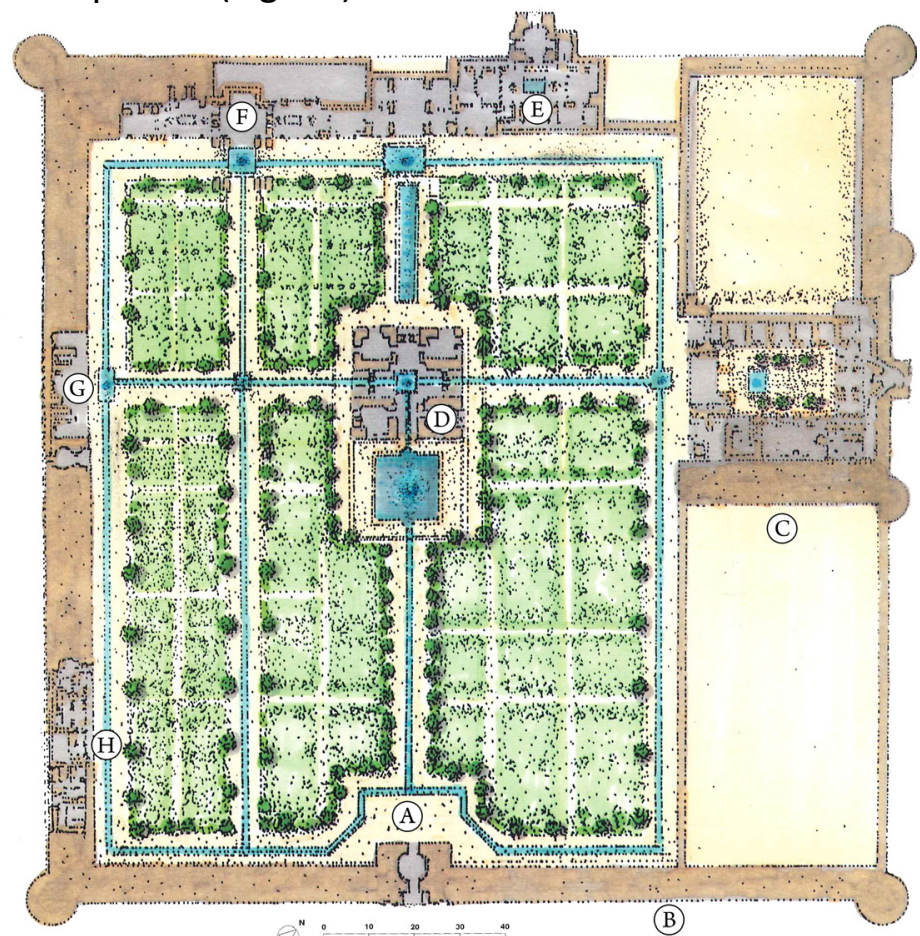

Figure 10. Hierarchy of spaces in Fin Garden plan (Khansari et al. 1998)

${ }^{1}$ Hashti as an architectural element in the traditional Iranian architecture is the semi-private space behind the doorway. Hashtis are designed in many houses, mosques, schools and baths. The function of the hashti is to weave the public area of outside to the private area of inside. 
The water streams usually define the path to the edifice. This principle can also be found in the height, color and size of garden component (Mehdizadeh Saraj \& Nikoo Goftar 2011).

\subsubsection{Symmetry}

Symmetry as a classical aesthetic tool has been an inseparable design principle in Persian gardens. Various aspects of symmetry can be found in the design of middle open spaces, palaces, streams and irrigation network, and the type and place of planting vegetation and trees, especially along the garden axes (Naghizadeh 2013) (Fig. 11). However, within this apparent symmetry, the vegetation provides a slight eye-catching asymmetry. In spite of the order of the planting system of the garden, plants cannot equally grow and they will differ with each other. In this sense, the garden is a symmetrical container, which embraces the asymmetry of its containerized natural elements.

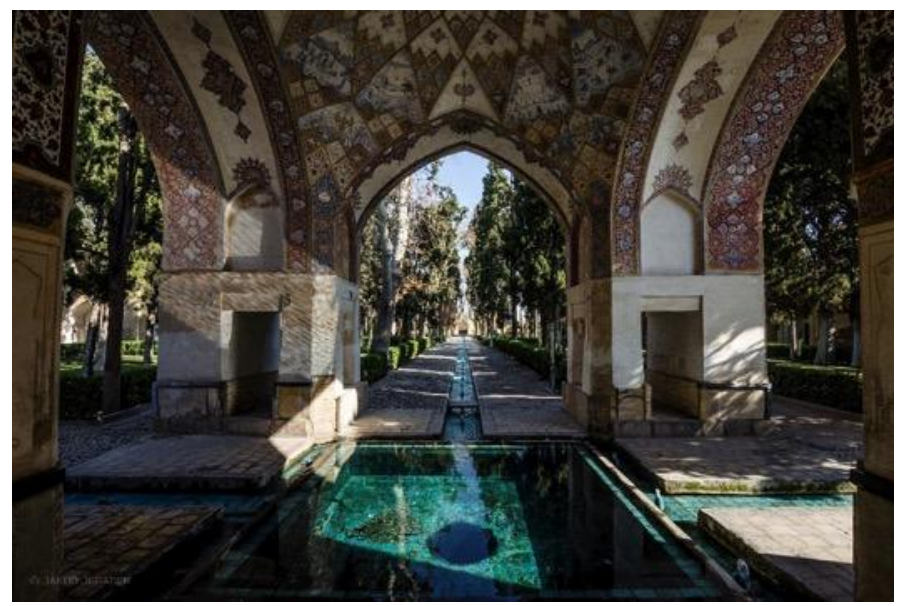

Figure 11 . The art of symmetry in all component of Fin Garden with view to four directions. Kashan. Photo by: Jakub Jerabek from Flickr

\subsubsection{Centrality}

In Persian gardens, the principle of centrality is mostly based on the placement of the pavilion as a focal point, located at the intersection of the garden's main axes. The centrality has been mostly intensified with the placement of the axes amplifying the symmetry, the location of the pavilion as a focal point and central space, the row of planted tall trees creating a surrounded pathway in the center and contrasting the color of the building materials with the landscape. In the Fin and Shahzadeh-Mahan gardens, the main pavilions have been located at the intersection of the axes with main pools in front, providing a simple pattern of chahar-bagh (Borazjani \& Javadi 2004).

\subsubsection{Rhythm and harmony}

Harmony had been used in different forms: in the regulation and design of gardens' elements such as the type and location of the vegetation, replicating the geometrical shapes, between the natural and architectural elements, use of fountains and ponds, flooring and design of the walls around the gardens. Moreover, the integration of a vertical linear system of trees and horizontal linear system of waterways and walkways provides a rhythm and harmony in the appearance of gardens (Sarbangholi \& Shahed 2012).

\subsubsection{Multiplicity in unity, unity in Multiplicity}

Although the simplicity of gardens' structure unifies the space holistically, it contains diverse spaces with simple geometrical shapes, diverse plants and vegetation, even diverse forms of presenting water. Despite all of these diverse and independent components, gardens' principles such as symmetry and centrality have created a unified and united space. All the elements function separately to pursue the purpose of the garden, develop the interaction between the human and the nature.

\subsubsection{Naturalism and enjoying the view}

Creating an association with nature has been the target of every garden builder. The creation of semiclosed spaces and presence of broad and open perspective without any visual barriers provides an opportunity to be engaged with the nature. Unlike European gardens, the philosophy and concept of 
Persian gardens do not seek to impose order into the landscape rather trying to arrange the components in their spatial order (Fig. 12).

Maintaining an open perspective in gardens has been a principle of planting and structuring (Pirnia 1994). Therefore, the front space of pavilions along the main longitudinal axis has been usually dedicated to an open and stretched space, which contains short vegetation or a large pool to avoid blocking the main view of the garden. The use of one point perspective aggravating by straight footpaths, the body of tall trees surrounding the footpaths and continues water channels in the middle could provide an infinite and boundless view to recall the paradise (Fig. 13).

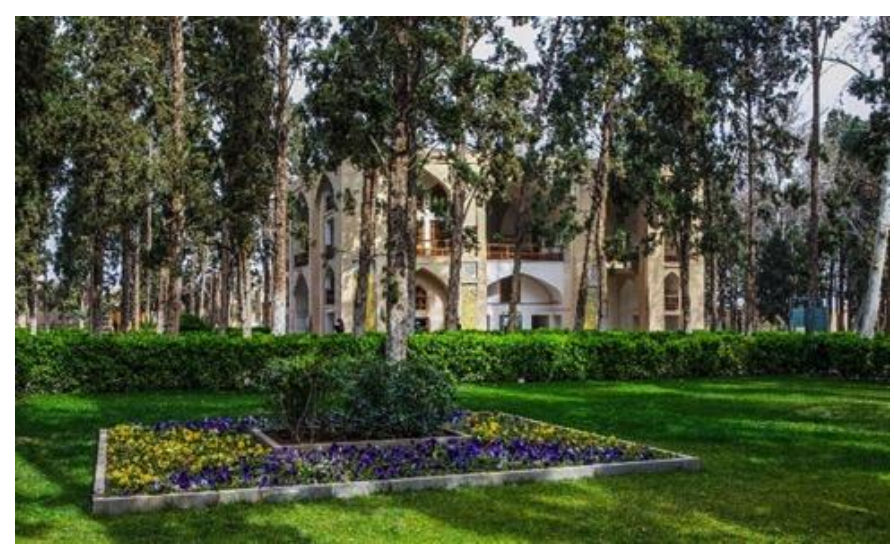

Figure 12. A view of natural environment of Fin garden. Kashan. Tall cypresses provide shades for most of the garden. The shrub roses, grass and violet flowers intensified the natural beauty of the garden. Photo by: Ninara from Flickr
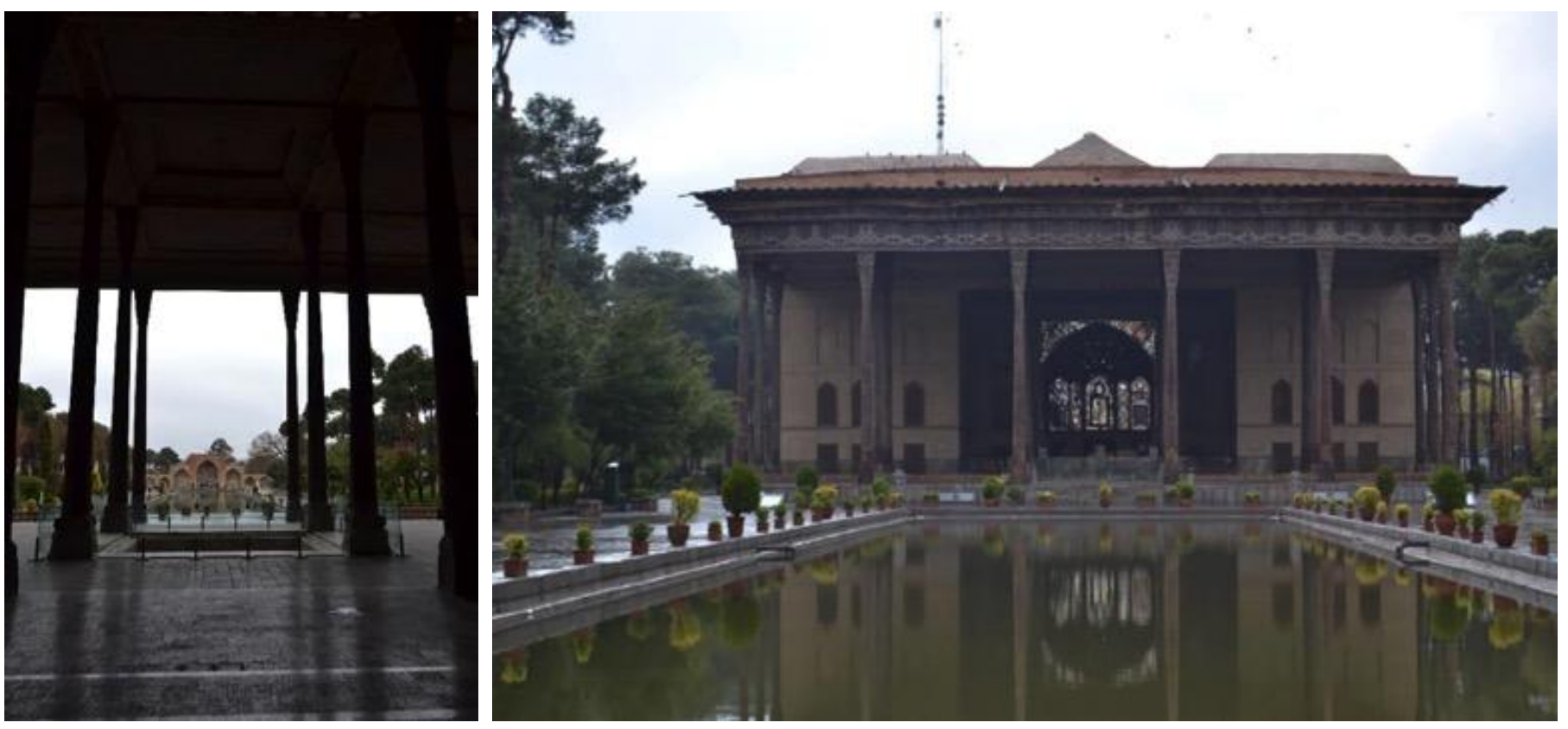

Figure 13. Openness of landscape in Chehel-Sotun garden, Esfahan. Photos by: Alan Cordova from Flickr

\section{Semantic values in Persian gardens}

Carc ulture and identity in a society can affect the architecture and the meanings intertwined with the architecture. Mythology and symbolism are the elements that may shape the culture and affect the architecture of a nation and, in this case, the garden. Architectural representation in a city can give substantiality and embodiment to the meanings and beliefs within a society. Either considered as myths or not, some objects were believed to be sacred throughout the ancient world. Objects such as sun, moon, water, tree and mountain were respectful to the ancient cultures. Some of these objects and their associated symbolism were utilized in Persian gardens and have affected their architecture, design and patterns.

The relationship between architecture and landscape might be rooted in the worldview of the society in regard to the nature. In eastern cultures, there has been a close relationship between the human and nature. In a sense, eastern nations knew 
themselves as a part of the nature. They did not consider human as the owner or dominator of the natural environment. In Persian gardens, all natural elements (water, trees, fruits and flowers) have congregated to produce a space, in which people can enjoy and praise the nature. Iranians have fabricated the perception of a paradise and the universe in their gardens in spite of the possibilities and limitations. The following section of this paper investigates the religious and cultural beliefs and their effects on the design and configurations of gardens and explores those parts of the garden that can be evocative of the true meanings.

\subsection{Garden as a symbol of the universe}

There is a debate among scholars regarding the meanings and implications of the word chahar-bagh. In the Persian language "chahar" means four and "bagh" means garden. Some scholars believe that the chahar-bagh concept refers to a garden divided into four parts via the water flow. However, several scholars argue that in the Iranian culture, chaharbagh is a metaphor of the cosmos (Alemi 1390; Brookes 1987). Alemi refers to the Heravi's definition of the garden as a universe whose architect is God and the human is a seedling planted and created by God (Alemi 1390). The number four in the Iranian historical culture is a symbol of universality, indicating the four directions in the universe, the four classical elements: water, earth, air and fire, four periods of creation (Alemi 1390; Faghih \& Sadeghy 2012).

Based on Henry Corbin's study on the Mazdean cosmology, Alemi argues that Persian chahar-bagh is a symbol of the universe, including the elements that can be found in a Persian chahar-bagh (Alemi 1390). In chahar-baghs, terraces symbolize the cosmic mountains and the creation of the edifice or throne at the highest level represents the position of the God. A great pool is placed in front of the edifice representing the cosmic ocean as the source of all waters which can irrigate the whole garden. The presence of trees, flowers and animals around the edifice complement the figure of the universe (Alemi 1390). According to Clark, Islamic Gardens have been designed based on the spiritual conception of the world and aim to strengthen the relationship between the visitor or user and God (Clark 2004) (Fig. 14).

\subsection{Water}

Geometry of Persian gardens is not only owing to the irrigation and agriculture principles, but also it is formed due to the beliefs, meaning, symbols, myths and the elements that form the Persian garden's identity. The early geometric form of the garden might be dictated by the practicalities of the irrigational system (Brookes 1987); however, the formation of the pattern of chahar-bagh seems to be much more than just the irrigation system.

In Persian gardens holiest of all elements and myths is water (Khansari et al. 1998) or as Moynihan describes it: "water is the most essential and central element in the Persian gardens" (Moynihan 1980). The symbolic significance of water among Iranians was initiated before the Islamic period. Anahita, the goddess of Zoroastrians, is considered as the goddess of all waters, which has the power of purification of men and women and the power of giving life to the creatures of the world. Tistrya is also the god of rains and fertility which leads the armies of Ahura Mazda (Khansari et al. 1998).

After Islam, the Quran further emphasized the
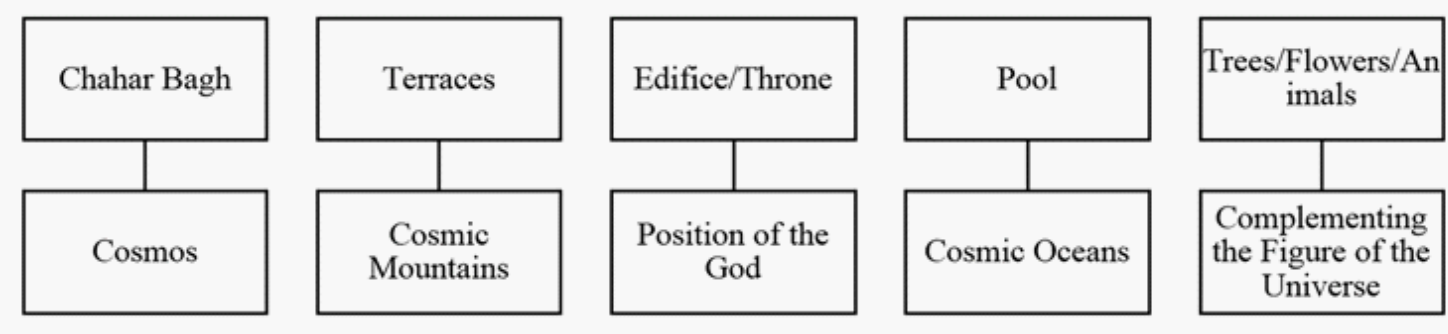

Figure 14. Symbolism in chahar-bagh, Source: author based on (Alemi 1390) 
centrality of water in the perception of Muslim Iranians. Muslims respect water as the most important means of cleaning and purifying. The Quran describes paradise as a garden beneath which rivers flow (Tabbaa 1987). The Persian garden's atmosphere is very similar to the image that the Quran has represented from the paradise as the retaliation of the good deeds, actions and manners. Additionally, water has been the element that could transfer the extremely arid lands of Persia to the quasi-paradise gardens.

The respect for water in the Iranian culture cannot be only because of the culture and the related meanings. But also it is owed to the water functional role in the production and maintenance of gardens. Especially, the vast amount of arid lands, shortage of rainfalls, sequential droughts and the harsh climate in a vast part of Iran have caused many Iranians to suffer from water insufficiency. The Creation of Persian gardens is owed to the exploration of water among the huge deserts of Persia. Therefore, water can be considered as the most significant element in Persian gardens, transferring a desert to a desirable microclimate usually inside walls in which trees and flowers can grow. The garden's existence depends on the presence of water, which can provide freshness and melodious sound.

In addition to the semantic and functional inscriptions, water plays an aesthetic role. In Persian gardens, water is a central element and the determinant of the axes (Fig. 15). This composition cannot be exclusive to the functional role of the water; since the designer could place water channels around the perimeter of the garden and in a less explicit expression. The presence of water in Persian gardens is the representation of its significance in the Persian culture. Water in Persian gardens flows and produces a desirable sound, affecting the acoustic aesthetics of the garden.

The geometric division of gardens has been usually achieved through the placement of water channels. Persian gardens were mostly segmented by water streams generating major and minor axes. Water is usually the identifier of centrality in Persian gardens. The water flows in the main axis of the garden to the pool in front of the edifice developing an architectural emphasis on the placement of the edifice. The water in Persian gardens is not a quite inert element; rather it is a dynamic tumultuous one either with its fountains and water jets or by the natural flow on the slope of the ground. The other feature of the water in Persian gardens is related to its reflection. The big pool in front of the edifice is usually a reflector of the pavilion and the greenery of the gardens adding another characteristic to the complexity of water in Persian gardens.

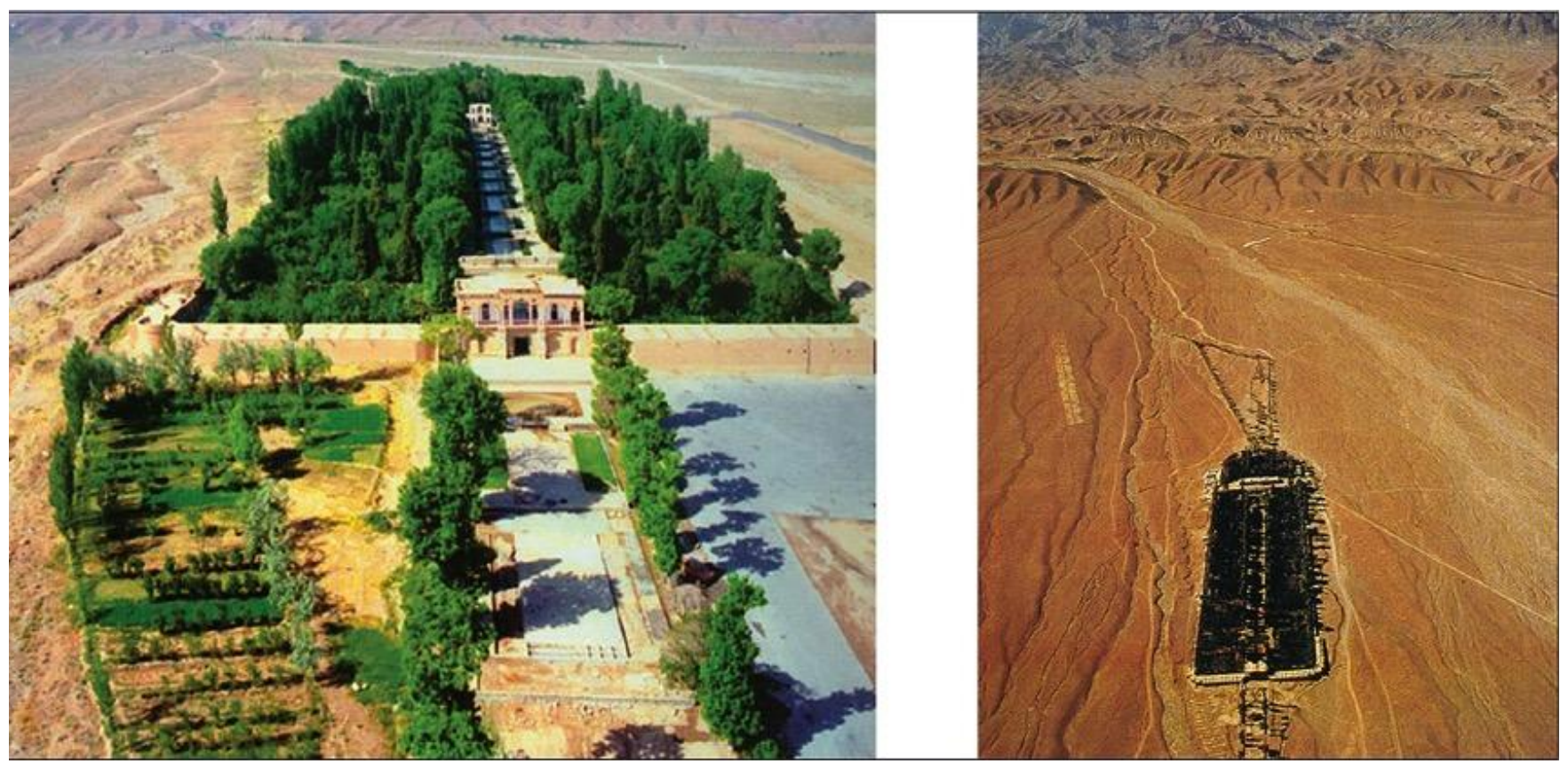

Figure 15. Water as the main element in Persian garden, Bagh-e-Shazdeh pools and water channels (Khansari et al. 1998) 


\subsection{Trees/shade and flowers}

Trees, and especially evergreen trees have the second-most important role after the water being the first (Taghvaei 2011). The presence of ever-green trees is firstly due to the users' need for shade and secondly is associated with the heaven's trees which are finitely green and fresh.

The first feature of trees is related to their semantic role. According to Zoroastrians, Amordad or Amshaspand is the guardian angel for plants and trees. Ancient Iranian also believed in the Life Tree (Goukarn or Hoom), which was assumed to have a healing power. Making or carving artificial plants, trees and flowers from the pre-Islamic era has been a symbol of the Life Tree. In Achaemanids' architecture (550-330 BC) 'life tree' has been propounded in the shape of a cypress tree and in relives of Sasanids' Period (224 AD to 651 AD), it has been in the shape of acanthus shrubs. After Islam, the Quran represents a similar metaphor, the tree of Tuba as the Heaven Tree (Ansari et al. 2008). According to Hobhouse, in Persian gardens, the evergreen cypress represented immortality and the flowering almond the regeneration of the earth in springtime, while the date palm could provide an allyear-round sustenance (Hobhouse 2003).

As well as the semantic features, trees play a significant functional and productive role in the life of gardens. Pattern of productivity is present in the nature of Persian gardens in which you can hardly find just a single plant. In each plot, there was usually a specific fruitful plant such as apricot, peach, apple and etc. This pattern of fruit productivity was clear in royal gardens, ancient gardens, recreational gardens and even traditional houses yards (Motallebi 2013). Cultivation of plants in Persian gardens follows a certain order, which is influenced by the geometrical configuration of the garden's design. The trees near the main pathway or near the plots were usually four-season trees, which were picturesque in the whole year. The trees with fewer leaves were usually planted in a further distance. Subtelny has illustrated the pattern of production in a typical chahar-bagh (Subtelny 1997) (Fig. 16).

Trees not only produce fruits and yields, but also provide shades, freshness and coolness. In the hot

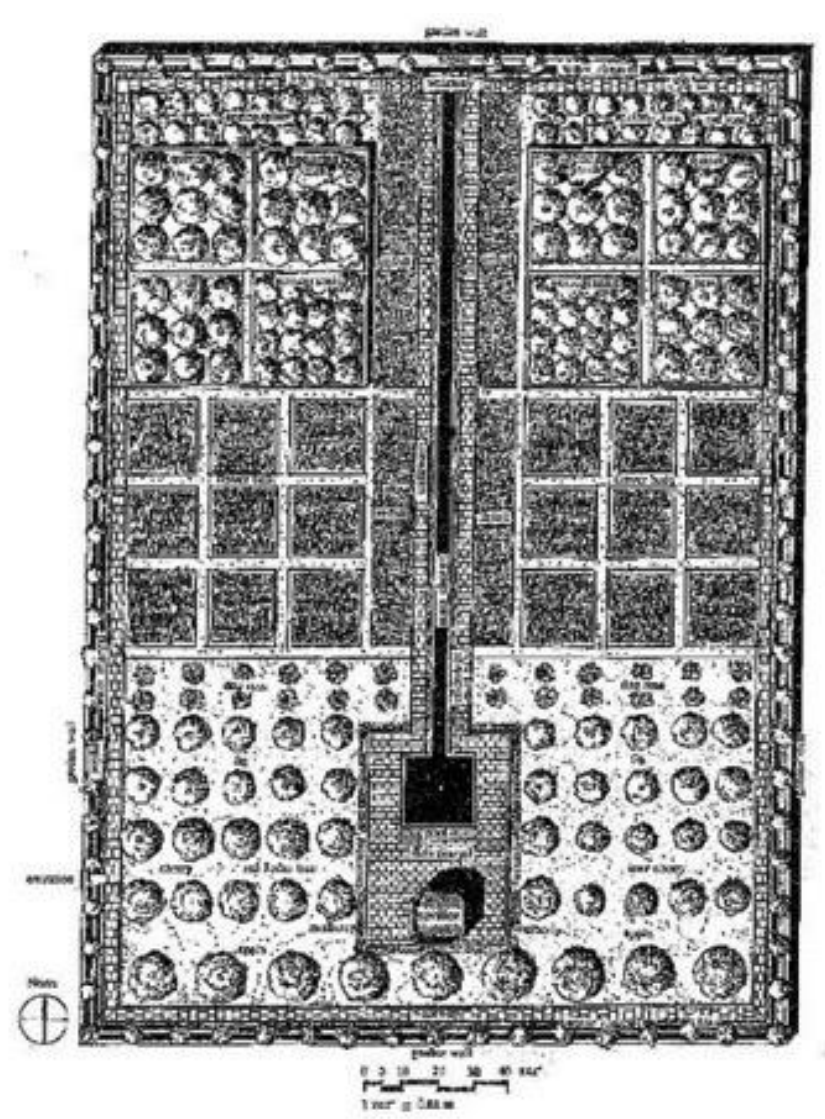

Figure 16. The pattern of production in a typical chahar bagh (Subtelny 1997)

arid lands of Persia, this freshness is very desirable and pleasurable. Trees' shades make the severe, hot and dry territories of Iran tolerable and even desirable like a paradise and this can intensify the Iranians' respect for trees and plants. Trees are either shady such as cypress, elm and sycamore or fruitful. The pathways (along the plots) were usually designed very narrow in order to be shaded by the shady trees. Cypress trees which inevitably appear in Persian gardens symbolize immortality. Cypresses often border the watercourses which divide the garden into plots (Moynihan 1980). Additionally the shade of trees prevents the excessive evaporation of the water flowing in channels. The surrounding trees define the axis and emphasize it in an aesthetical way.

Trees are not only designed and planted in the Persian gardens, but also crafted and utilized in the architecture and ornaments of Persian gardens' pavilions. The Archimedean art is filled with different 
types of tree of life. In Persepolis, water Lily is seen in different forms. On the other hand, in the Iranian garden, each plant has its own special symbol and sign (Shahidi et al. 2010).

\section{Discussion}

$\mathrm{C}$ ulture is concerned with the production and exchange of meanings between a nation or society or as Hall describes it 'culture is about shared meanings' (Hall 1997). Language is the most frequent media or interface through which thoughts, ideas and meanings are represented in a culture. In this sense, design and architecture can be considered as a a less frequent and less discussed media of representation. Design can also be the media of thoughts and meaning to the next generations. As language is central to the meanings and culture so is the architecture and in this matter gardens' design.

According to Hall, things get their meanings and values through their representation (Hall 1997). Hall's ,circuit of culture' suggests that, meanings are produced at several different sites and circulated through several different processes or practices. One of these practices is the architectural discourse of a city and its elements. Meaning is what gives us and our architecture a sense of identity, of who we are and to whom we belong. Design and architectural representation of a nation are fluctuating between all the other elements of the circuit (Fig. 17).

Despite of all the meanings, symbols, values and respects of Iranians for the paradise, water and trees, it can be hardly proven that the formation of Persian gardens is merely the result of these beliefs. As meanings are fluctuating between nations and generations, many architectural manifestations in Persian gardens are also present in Persian traditional houses and even mosques. Elkins claims that garden history unlike the history of painting, sculpture, and architecture, has no conceptual foundations (Elkins 1993). However, similarity of Persian gardens to Persian architecture (of traditional houses, mosques and etc.) in several elements including, structure and material, form and symmetry, arches and ornaments shows that Persian garden has been a product of

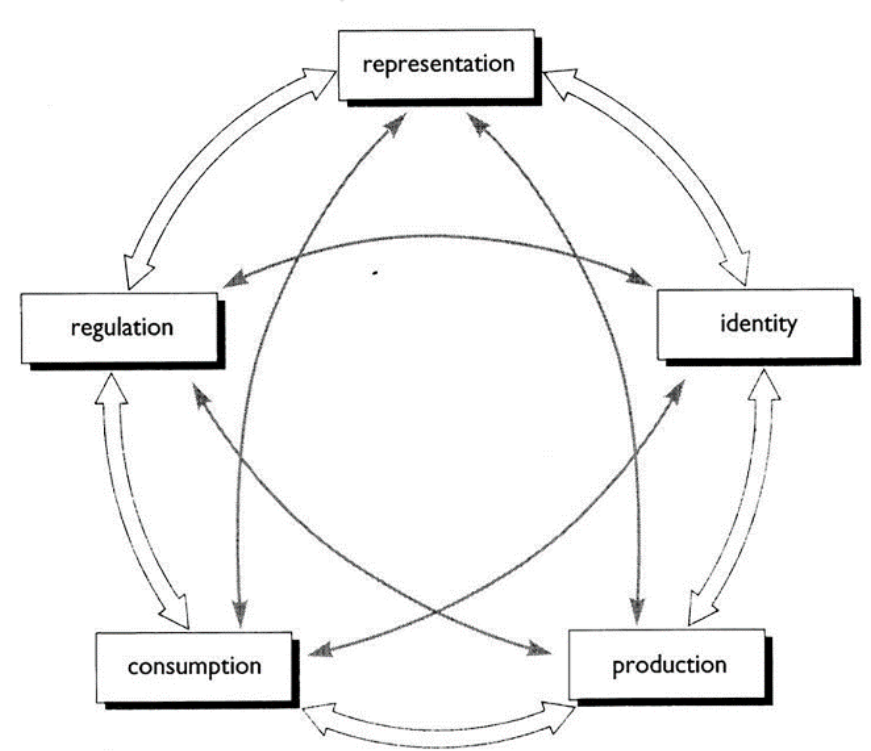

Figure 17. The Circuit of Culture (Hall 1997)

Persian culture and the meanings intertwined with the culture. As Moynihan argues the Persian garden is derived from native conventions rather than a royal enjoyment, which have caused the continuity of the tradition and a symbolic topography of the paradise garden (Moynihan 1980).

A few scholars argue that miniature paintings, imaginative writing and the Quran have been the main sources of the garden's formation and the quest for ideal/perfect paradise (Brookes 1987); a key problem with this argument is that Persian gardens have been designed well before the formation of Persian literature and miniature and even the birth of Islam (Fig. 18). Rather the imagination in poetry and literature can be a product of the Persian gardens and in this sense, the architecture and culture.

Persian gardens were not always exclusive to royalty and royal gardens, rather they were found connected to simple homes and settlements. The scale would be obviously different in smaller gardens, but the meaning and design would stay intact. As an example, Narenjestan Ghavam house in Shiraz is surrounded by a large yard very similar to a chahar-bagh (Fig. 19). Even when the family was not wealthy enough to have a garden such as Narenjestan Ghavam, Persians uses to decorate their internal yards as a kind of a miniature garden within their traditional house. 


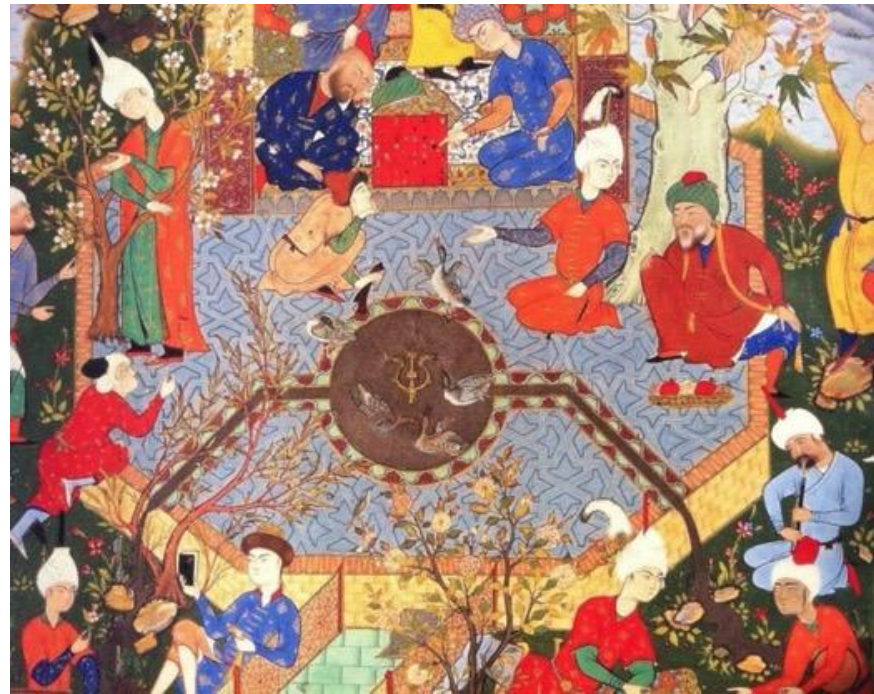

Figure 18. Safavid 16th c. miniature from "The Seven Thrones" of Jami (Khansari et al. 1998)

Having said that Persian garden is very similar to other elements of Persian architecture, there are still features that seem to be conflicting. The most obvious dissimilarity of Persian garden to a Persian traditional house $^{2}$ or traditional architecture can be the attitude of the garden's edifice toward outside. As opposed to the Western approach of concentration on the external look of a house, traditional settlements of Iran are mostly in an introvert form, concerning the space within in order to achieve privacy (Brookes 1987). However the converse form, exhibiting an outward-directed dynamism is found in Persian gardens where the pavilion is looking outside to the garden and the external façade is in touch with the surroundings (Fig. 20). In spite of this dissimilarity, the privacy in Persian gardens has been achieved through the short walls surrounding the garden. Therefore, the Persian garden with all its outward expression remains an enclosed/introverted feature of Iranian architecture (Brookes 1987).
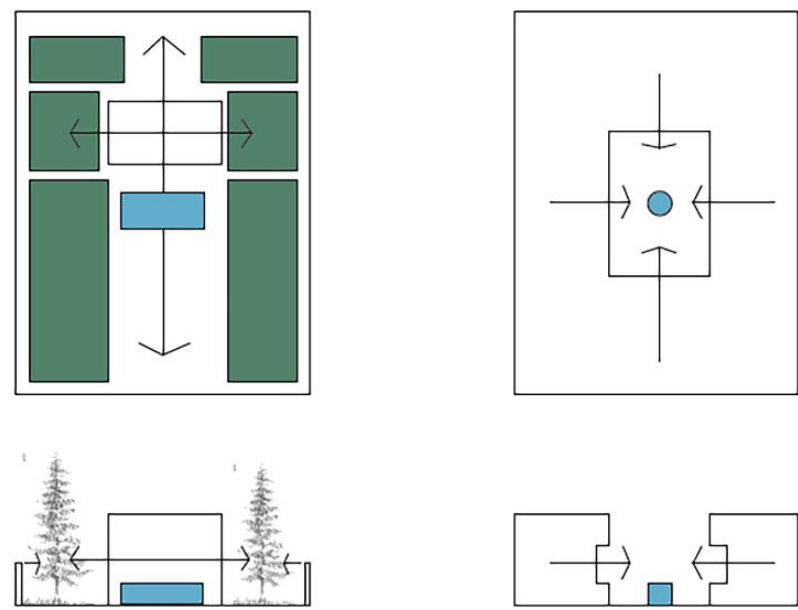

Figure 20. Comparing an extrovert garden to an introvert traditional house. Source: author

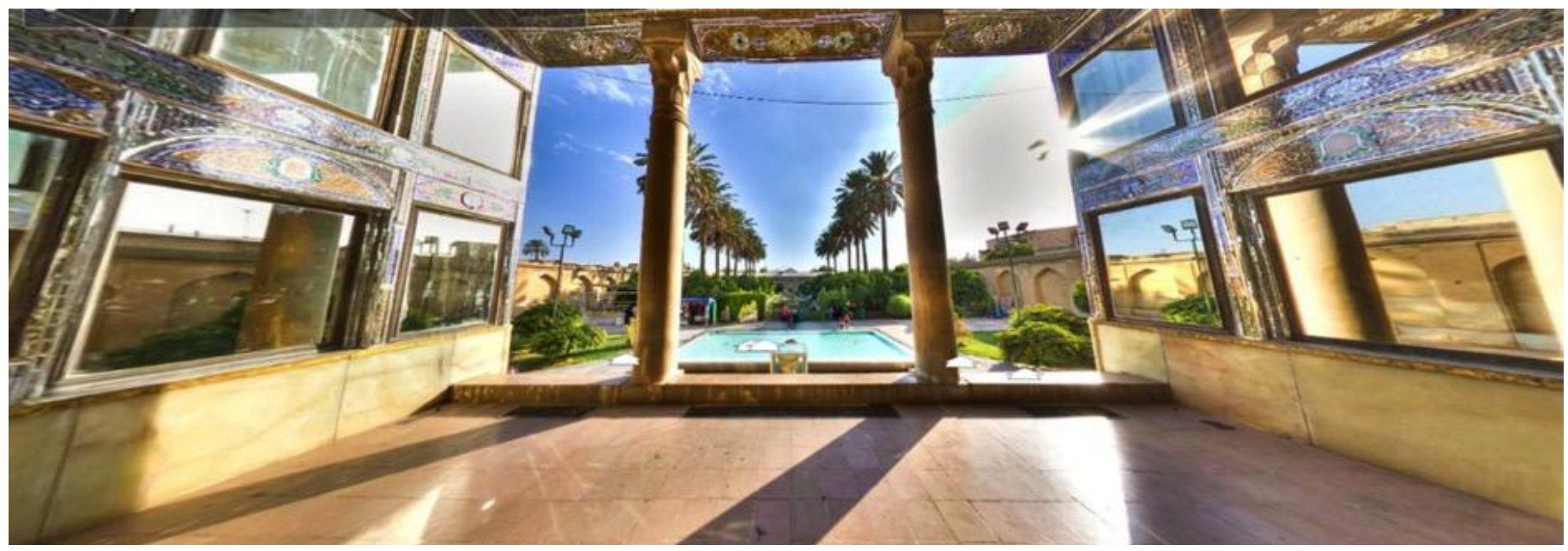

Figure 19. Narenjestan Ghavam house in Shiraz with a yard as a miniature garden, photo by: Mohammad Reza Domiri Endnotes: ${ }^{2}$ In the hot and arid climate 


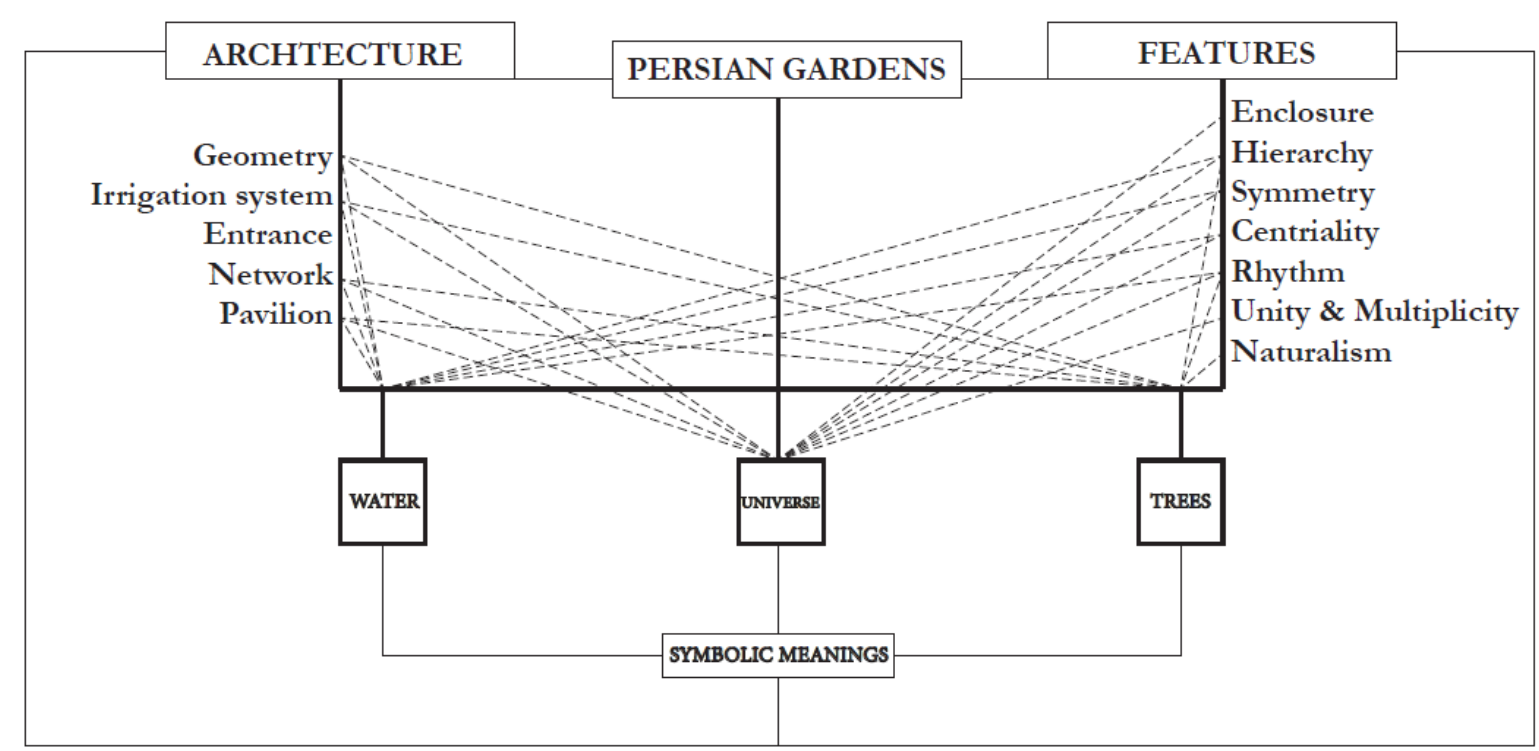

Figure 21. Relationship between symbolic meanings and Persian gardens features and architecture. Source: Own work

The model above summarizes this paper and analysis and demonstrates the Persian gardens architectural specs and features. It shows that symbolic meanings within Persian gardens are mostly about the representation of the universe and elements such as water and tree. It also shows how each symbolic meaning is shown in specific design features (dashed lines). The irrefrangible bond between the garden design and associated meanings has maintained the garden design features intact between Safavid and Qajar Dynasty.

This paper stresses that the design of Persian gardens has been shaped based on meanings, beliefs and symbolic elements of Iranian culture. It argues that culture and public beliefs and values have shaped the garden architecture and this architecture is a representation of people's beliefs and culture. Therefore, historically culture and Persian garden architecture (as a model of Persian architecture) have been interactive. In this sense, as much as the architecture has been the representation of cultural values, the values have acted as a medium affecting the architectural form and composition.

These meanings weaved into the structure of Persian garden have granted an identity to these places. Water, plants, walls and trees are the elements of identity. Although, in the contemporary society, Persian garden has become a national identity, their meanings and associated values are not utilized in the design of contemporary landscapes. Sometimes an imitation of Persian gardens in the form of geometrical quadripartite division can be seen in the plan of contemporary parks and gardens without much attention to their underlying values and beliefs.

\section{Conclusion}

C ulture is concerned with the production and exchange of meanings within a nation or society. Architectural discourse of a city and its elements are the interfaces through which thoughts, ideas and meanings are represented in a culture. In this sense, gardens are considered as symbolic sites that represent meanings and values through their design. Focusing on Persian gardens as the case study, this paper explored the design characteristics of Persian gardens and how meanings and symbolism have affected this design from a built environment perspective.

Several scholars argue that in the Iranian culture chahar-bagh is a metaphor of the cosmos. In this sense, Persian garden is considered as a universe whose architect is God and the human is a seedling planted and created by God. The number four in the 
Iranian historical culture is a symbol of universality, indicating the four directions in the universe, the four classical elements: water, earth, air and fire, four periods of creation.

Persian chahar-bagh is a symbol of the universe. In chahar-baghs, terraces symbolize the cosmic mountains and the creation of the edifice or throne at the highest level represents the position of the God. A great pool is placed In front of the edifice representing the cosmic ocean as the source of all waters which can irrigate the whole garden. The presence of trees, flowers and animals around the edifice complement the figure of the universe. Islamic Gardens have been designed based on the spiritual conception of the world and aim to strengthen the relationship between the visitor or user and God.

Additional to the holistic semantic view of the Persian garden as the universe, various elements of gardens embrace their own meanings and semiology. Water and trees are considered as the most important elements in the creation of Persian gardens. Their meanings and significance have been represented through their design and placement in Persian gardens. Water channels shape the axes in Persian gardens and define the plots of vegetation intensifying the placement of the edifice. Water channels also perform as the symmetrical axes of the garden intensifying the centrality. All the elements of the garden perform together to provide a suitable context for the plots of vegetation. Different trees and flowers have their own site and setting designed by the garden builder and in line with the function of the garden. After water, trees have the second most important role in the garden elements in terms of meanings and semiology.

\section{Acknowledgements}

The authors would like to thank all the people who helped us in providing the visual materials of this paper. The constructive comments provided by the anonymous referees are also gratefully acknowledged.

\section{References}

Alemi, M. 1390. Symbolism in persian gardens: the nature sense in the Safavid royal gardens. Manzar 17.

Alon-Mozes, T. 2004. Gardens and the emergence of culture: The Meir Garden: The first Hebrew garden for the first Hebrew city-Tel Aviv. Studies in the History of Gardens \& Designed Landscapes 24, 55-64.

Ansari, M., A.A. Taghvaee \& H.M. Nejad. 2008. Cultural Beliefs Regarding Persian Gardens with the Emphasis on Water and Trees. African and Asian Studies 7, 101-124.

Babaie, S. 1997. Paradise contained: nature and culture in Persian gardens. Studio Potter 25, $10-$ 13.

Bacon, F. 1883. Of gardens (1625). In: Dixon Hunt, J. and WP.Willis (eds). The Genius of the Place - The English Landscape Garden 1620-1820. London. 51-56

Borazjani, V. \& M.R. Javadi. 2004. Persian Garden: Ancient Wisdom, New Perspective. Contemporary Arts Museum of Tehran Publications. Tehran.

Brookes, J. 1987. Gardens of paradise: the history and design of the great Islamic gardens. New Amsterdam Books, New York.

Clark, E. 2004. The art of the Islamic garden. Crowood Press, Michigan.

Elkins, J. 1993. On the conceptual analysis of gardens. The Journal of Garden History 13, 189-198.

Faghih, N. \& A. Sadeghy. 2012. Persian Gardens and Landscapes. Architectural Design 82, 38-51.

Gharipour, M. 2011. Transferring and transforming the boundaries of pleasure: multifunctionality of 
gardens in medieval Persia. Garden History 39, 249-262.

Hall,S.1997. Representation:Cultural representations and signifying practices Sage Publications.

Hobhouse, P. 2003. Gardens of Persia / Penelope Hobhouse. Florilegium, Glebe, N.S.W.

Hunt, J.D. 2000. Greater perfections: the practice of garden theory. University of Pennsylvania Press.

ICHHTO (The Office of Cultural Heritage of Iranian Cultural Heritage, H.a.T.O. 2010. The Persian Garden_UNESCO: World Heritage. http://whc. unesco.org/uploads/nominations/1372.pdf (Date: 10.01.2016).

Karimi-Hakkak, A. 1998. Iranica heirloom: Persian literature. Iranian Studies 31, 527-542.

Khansari, M., M.R. Moghtader \& M. Yavari. 1998. The Persian garden: echoes of paradise. Mage Publishers Washington, DC.

Mansouri, S.A.N., H V. 2011. Chahar Bagh. A study of the origin of the Chahar bagh concept as a model for Iranian Gardens. Manzar 14, 16-23.

Massoudi, A. 2009. Acquaintance with Iranian Gardens Bagh-e Shazdeh. Faza Publication, Teheran.

Mehdizadeh Saraj, F. \& A. Nikoo Goftar. 2011. A Comparative Study on Approaches to Achieve Tranquility, Calmness and Meditation in Traditional Gardens of Iran and Japan. Bagh-INazar 17, 31- 43.

Motallebi, R. 2013. Existence Sound of Iranian garden. Manzar: The Iranian Scientific Journal of Landscape. 4, 50-51.

Moynihan, E.B. 1980. Paradise as a Garden: In Persia and Mughal India. Scolar Press London.
Müller-Wille, S. 2001. Gardens of paradise. Endeavour 25, 49-54.

Naghizadeh, M. 2013. Representations of beauty in Persian gardens. Manzar: The Iranian Scientific Journal of Landscape 5, 6-9.

Pirnia, M.K. 1994. Iranian Gardens. Abadi journal 4, 67-74

Sarbangholi, S.H. \& M. Shahed. 2012. Review of similarities between Persian musical concept and architecture of persian garden (Case study: Kashan Fin garden). Memari va Shahrsazi Arman Shahr 9, 97-110.

Shahidi, M., M.R. Bemanian, N. Almasifar \& H. Okhovat. 2010. A Study on Cultural and Environmental Basics at Formal Elements of Persian Gardens (before \& after Islam). Asian Culture and History 2, P133.

Subtelny, M.E. 1997. Agriculture and the Timurid Chahargagh: The evidence from a medieval Persian agricultural manual. In: Petruccioli A. (eds) Gardens in the Time of the Great Muslim Empires: Theory and Design. E.J. Brill. Leiden, New York, Cologne. 110-128.

Tabbaa, Y. 1987. Towards an interpretation of the use of water in Islamic courtyards and courtyard gardens. The Journal of Garden History 7, 197220.

Taghvaei, S. 2011. The Totality of the Garden and the Evergreenery Secret. Manzar: The Iranian Scientific Journal of Landscape 3, 6-11.

Tajaddini, L. 2011. Review of the Characteristics of Mahan Garden: One Type of Persian Gardens. World Academy of Science, Engineering and Technology 5, 1264-1267.

Wilber, D.N. 1962. Persian gardens and garden pavilions. Rutland, Tokyo. 